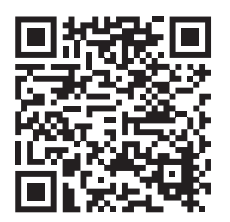

* Médico Pediatra Especialista en Alergia en Inmunología Clínica. Subdirector de Pediatría Ambulatoria Hospital Infantil de México Federico Gómez.

Correspondencia: JJLSM, jjsienra@hotmail.com Conflicto de intereses: No existe conflicto de intereses.

Citar como: Sienra MJJL. COVID-19 y el paciente asmático en el consultorio. Rev CONAMED. 2020; 25(supl. 1): s24-s30. https:// dx.doi.org/10.35366/97345 Financiamiento: No hubo financiamiento.

Recibido: 13/17/2020. Aceptado: 13/11/2020.

\section{COVID-19 y el paciente asmático en el consultorio}

\author{
COVID-19 and the asthmatic patient in the clinic
}

José Juan Luis Sienra Monge*

\section{RESUMEN}

Los síntomas de COVID-19 son muy similares a los de los pacientes asmáticos o alérgicos, se pueden llegar a confundir por la tos, la sensación de cansancio, la falta de aire o rinorrea; es importante mencionar que pueden coexistir dos padecimientos. La presencia de sibilancias y la respuesta al tratamiento es lo que marca la diferencia en un paciente asmático. Éste está en el grupo de mayor riesgo al tener una enfermedad pulmonar crónica, por lo que debe estar en constante comunicación con su médico especialista para evitar agentes desencadenantes de las crisis asmáticas.

Palabras clave: COVID-19, asma, alergias.

\begin{abstract}
The symptoms of COVID-19 are very similar to those of asthmatic or allergic patients, they can be confused by coughing, feeling tired, shortness of breath or rhinorrhea, it is important to mention that two conditions can coexist. The presence of wheezing and the response to treatment is what makes the difference in an asthmatic patient. The asthmatic patient is in the highest risk group, having a chronic lung disease so he must be in constant communication with his specialist doctor to avoid triggers of asthmatic attacks.
\end{abstract}

Keywords: COVID-19, asthma, allergies. 


\section{INTRODUCCIÓN}

Desde hace más de seis meses se ha publicado diverso conocimiento sobre la COVID-19, y pese a que ya existen miles de publicaciones, todos los días hay algo nuevo por aprender. El objetivo de la siguiente publicación es abordar dos problemas de salud: asma y COVID; uno antiguo y uno reciente, pero los dos muy importantes. Por lo que se tratará de explicar cómo evaluarlos, sus motivos, sus tratamientos, la coexistencia de estas dos patologías, los efectos en la salud, cómo tratar y prevenir los contagios, y cómo regresar a una vida normal dentro de la pandemia.

\section{ASMA Y ALGUNOS ESTUDIOS}

El asma es una enfermedad heterogénea en la que se habla de un problema inflamatorio crónico de las vías respiratorias; presenta síntomas como sibilancias, dificultad respiratoria, sensación de opresión torácica, que en los niños se traduce como dolor, tos seca y persistente (principalmente en la noche), y esto varía con el tiempo, la intensidad puede aparecer y desaparecer en poco tiempo o puede tener relación con algún evento del día o con la presencia de algún alérgeno que se encuentre en el ambiente.

De su epidemiología se sabe que hay más de 300 millones de pacientes afectados en el mundo; y día con día se van sumando más casos, ya que es una enfermedad que afecta más a las zonas urbanas que a las rurales y el mundo cada vez se está concentrando más en las zonas urbanas.

Nuestro país no está exento de este problema, hace ya 15 años hicimos un trabajo sobre la epidemiología y encontramos que más o menos $8 \%$ de los niños y $9 \%$ de los adolescentes tenían datos o síntomas de asma. Es un número muy importante que debemos tener en consideración.

También existen problemas para poder lograr un diagnóstico definitivo, pues podemos llegar a diferentes hipótesis como decir: "esto se trata de asma» o «esto se parece el asma» o «sólo tiene sibilancias».

A continuación, mostramos los datos de un trabajo de hace casi 20 años de la Dra. Hellen Brooke Taussig, el cual dividió a los niños con sibilancias, que fueron seguidos por varios años y divididos en tres grandes grupos. El primero se denominaba del sibilante transitorio y de este grupo la característica principal es que tenía un ruido en el pecho y silbaba en forma episódica, sólo a veces tenían algo de dificultad respiratoria. Estos episodios se presentaban en los primeros tres años de vida y sobre todo en los que fueron prematuros o tenían antecedente de tabaquismo parenteral.

En el segundo grupo, las sibilancias eran de forma recurrente, éstas se asocian a enfermedades virales. Quizás sea el que más predomina en niños antes de los tres años y cada vez que les da un proceso viral respiratorio presentan sibilancias, sin datos de alergia y generalmente para la edad escolar desaparece.

Por último, en el tercer grupo, estaban aquellos que no empiezan después del primer año de vida, no está relacionado con prematurez, tabaquismo ni con infecciones. Normalmente son cuadros persistentes y va en aumento progresivamente. Se asocian a problemas alérgicos, completan los parámetros de la definición de asma, tienen tos, sibilancias, son recurrentes y por lo general es persistente hasta la edad adulta. Es lo que todos los autores realmente consideran como asma. Este tipo de cuadros son los que a la larga se van a presentar; sin embargo, no se sabe si se presenta desde el primer año de vida y en qué va a acabar.

\section{ÍNDICE PREDICTIVO PARA EL ASMA}

El Dr. Castro Rodríguez publicó un estudio en el que recomienda un índice predictivo para tratar de dilucidar si un niño que presentó sibilancias en alguna etapa de su vida llegará a ser asmático o en qué va a acabar. Lo que se encontró en este estudio fue que $40 \%$ de los niños menores de un año tenían por lo menos un episodio de sibilancias, un porcentaje realmente considerable. También se encontró que $80 \%$ de los adultos asmáticos ya estaban diagnosticados o habían tenido síntomas antes de los tres años. Por otro lado, 30\% de los sibilantes preescolares seguían con síntomas después de los seis años. Ante dicha evidencia surge entonces la duda, ¿existirá el asma como tal antes de los tres años? Esta cuestión aún no ha sido esclarecida.

Este índice predictivo tiene como objetivo tratar de identificar factores de riesgo que indiquen que un paciente tiene más probabilidades de ser 
asmático. Los criterios del índice están divididos en mayores y menores: dentro de los mayores se encuentra primero la herencia, es decir, que alguno o ambos padres tuvieran diagnóstico médico de asma o alergia, donde se consideró al eccema por ser parte de una enfermedad alérgica, al igual que la alergia alimenticia. En los criterios menores se considera la alergia respiratoria de la nariz, que tuvieran sibilancia sin diagnóstico de asma, pero independiente de los factores asociados (infecciones), y que la cuenta de eosinófilos fuera mayor a $4 \%$. Con este índice se llega a un resultado, que de ser positivo lo más probable es que el niño será asmático en un futuro.

\section{¿Cuál es la importancia de que tengamos un índice predictivo?}

Por lo general, en el asma hay episodios de estrechamiento de la vía aérea, infiltración celular, edema, inflamación, hipersecreción y contracción del músculo liso; y estos eventos, en la mayoría de los casos, se recuperan completamente y no deja ninguna lesión. Sin embargo, en aquellos que serán asmáticos, existe un daño que se produce en los cuadros progresivos, el estrechamiento será constante y causará alteraciones celulares a las que se les llama «remodelación de la vía aérea». El peligro es que esta remodelación puede ya no tener una recuperación total, dejando dañado el tejido broncopulmonar. Entonces, si se pudiera saber quiénes van a ser asmáticos, tendríamos que cuidarlos con más atención para evitar que tengan cuadros progresivosy, por lo tanto, la remodelación de la vía aérea.

\section{¿CÓMO SE CLASIFICA A LOS PACIENTES ASMÁTICOS?}

De acuerdo con su edad: lactantes, escolares y adolescentes. Por sus fenotipos o tipos de asma: a los que tienen muchos desencadenantes (por ejercicio, alergia, obesidad) o algunos en los que no se tiene la menor idea. Otra clasificación es de acuerdo con la frecuencia e intensidad con la que presentan los cuadros (intermitente o persistente, leve, moderada o grave). Finalmente, por cómo responden al tratamiento (bien controlado, moderadamente controlado o no controlado).
¿Cómo saber si nuestro paciente está controlado? De acuerdo al tratamiento adecuado, el número de síntomas que presenta en una semana y que tenga rescatadores de acción rápida (SABA, por sus siglas en inglés). Si tiene alguna de estas respuestas y se despierta en la noche o tiene limitaciones habrá que modificar su estado de bien controlado a parcialmente controlado o no controlado. Esto deberá advertir que el tratamiento no está funcionando como se esperaba. Muchas veces no funciona porque no se detectó alguna comorbilidad o porque no se le ha enseñado al paciente cómo debe utilizar el tratamiento.

\section{GUÍAS DE MANEJO DEL ASMA}

Ante este hecho, las organizaciones internacionales dirigidas a la atención global del manejo del asma (CINA), crearon guías en las que sugieren el manejo del asma de forma genérica; éstas se dividen en pasos: desde el uno (que son los más leves) al cinco (que son los más graves), además de los pasos intermedios y qué hacer con su tratamiento.

Este tipo de cuadros no son obligatorios de seguir; sin embargo, nos guían mucho para ubicar a nuestro paciente, dónde estamos y qué le vamos a hacer. Por ejemplo, se sabe que tenemos que darle un broncodilatador en casos agudos, pero también se sabe que cuando son cuadros muy leves se debe utilizar poca medicina y que se requieren cantidades diferentes de acuerdo a la evolución.

Esta iniciativa global para el asma se revisó el año pasado y se detectó que en muchos de los cuadros que considerábamos leves se usaba un exceso de $\beta_{2}$ agonistas; que este exceso, disminuía la respuesta a dichos medicamentos. De igual manera, se detectó que muchos de los adultos con asma fatal estaban con cuadros leves; muchas veces no se ponían los antiinflamatorios que son el tratamiento ideal para esto. Lo anterior motivó a que se sugiriera dar controladores desde el primer momento, utilizar combinaciones, inmunoterapia en casos alérgicos y medicamentos biológicos en cuadros graves.

Anteriormente en la guía, en el paso uno, que era el asma leve intermitente, decía que sólo le diéramos al paciente un broncodilatador de acción rápida por razón necesaria. En la actualidad, se indica que se le dé un broncodilatador de acción larga como el 
formoterol o cualquier otro, junto con un esteroide inhalado para prevenir el proceso inflamatorio y que se le diera por necesidad, no continuo. Si esto no lo resuelve, se puede también cambiar el broncodilatador de acción prolongada por uno de acción rápida, junto con un corticoide inhalado. En caso de que no funcione se pasa al siguiente paso, es decir, al paso dos y se utiliza el broncodilatador de acción prolongada, con esteroide inhalado en forma continua y en algunos casos agregar Montelukast.

Los pasos uno y dos son los que generalmente ven los médicos no especialistas en asma en el consultorio y representa de 80-90\% de los pacientes. Ya en los pasos tres, cuatro y cinco se agregan otros medicamentos como esteroides, biológicos, interleucina 5, entre otros, y tienen que ser vistos por un especialista. La guía se puede consultar fácilmente en Internet.

Todo lo anterior aplica para adultos y adolescentes, en los niños de seis a 11 años es prácticamente lo mismo, pues utilizamos los mismos medicamentos siendo un poco más enfáticos en el control, sobre todo en los factores desencadenantes como alergia de alimentos o a inhalantes. Cabe señalar que en niños menores de cinco años no está indicada la utilización de los controladores tipo esteroides inhalados junto con el broncodilatador de larga acción. En este caso en particular, desde el paso dos, utilizar antileucotrienos junto con todo lo demás y revisar caso por caso para ver riesgo beneficio. Pero ¿por qué sucede esto?, porque se llega a la discusión si existe asma antes de los tres a cuatro años.

Ya vimos que con las recomendaciones mencionadas en la guía podemos controlar a la mayoría de los pacientes, pero ¿qué es lo que generalmente sucede? La falta de apego por parte de los pacientes y sus familiares y la dificultad que tenemos los médicos para explicar cómo usar los medicamentos que estamos dando es el principal obstáculo, ya que pensamos que es muy sencillo utilizar un aerosol, pero se lleva tiempo de entrenamiento; además, hay que ser enfáticos en qué utilizar, sobre todo en estos tiempos en los que tenemos un virus que se transmite por aerosoles, por lo tanto, debemos ser muy cuidadosos en la terapia inhalada. Hay que asegurar que el espaciador esté acorde al tamaño del niño, pues si es muy pequeño o muy grande no es útil.

\section{COVID}

Por otro lado, está el problema de una gran pandemia que está afectando a muchísima gente, un virus que es sumamente contagioso, con factores virales que actúan con rapidez y que aunado a diversas comorbilidades lo vuelven aún más letal; y aunque la mayoría de los casos son leves mucha gente se contagia. Por lo tanto, si hablamos de muchos contagiados contra muchos asmáticos, es casi seguro que tendremos pacientes asmáticos contagiados, y eso es lo que nos llevará a que tengamos un especial cuidado.

¿Qué vamos a hacer con este virus? Todos los días aparecen 100, 200 o hasta 300 artículos diciendo que tal medicamento sirve, pero al día siguiente ese mismo resulta no servir, y lo único que realmente sabemos es que sólo algunos antivirales pudieran funcionar, y no en todos los casos. Todo lo demás es únicamente de soporte para los síntomas que nos vamos encontrando y para el daño celular que se va provocando por la liberación de citocinas, por la liberación de mediadores químicos que producen inflamación y todo el resultado de la activación del virus. Con base en ello, tenemos que ir dando medicamentos ante lo que nos vamos encontrando, por lo tanto, la medicación de los pacientes será sólo conforme su organismo vaya reaccionando. No hay nada que quite el virus antes de que llegue, no hay nada que lo quite en fases iniciales hasta ver qué está sucediendo, hasta el momento que aparezca la vacuna. La vacuna actualmente, siendo muy optimistas, podría salir para fin de este año; sin embargo, no hay ninguna certeza. La elaboración de vacunas no es tan fácil, y se tienen que realizar múltiples ensayos con ellas para evitar mayores riesgos.

\section{ASMA Y COVID}

Entonces, nos enfrentamos a grandes retos y dilemas, hay pacientes asmáticos y no asmáticos que tienen COVID. ¿Cuál es su cuadro clínico? Al principio parecería que es muy fácil: fiebre, dolor de cabeza, tos, disnea, pero gradualmente se van agregando síntomas. Hoy en día se ha validado la presencia de anosmia y disgeusia, síntomas que debemos vigilar más, porque posiblemente 
empiezan desde etapas tempranas. También hay que pensar en los factores de riesgo, en nuestra población tenemos un problema muy serio, mucho más serio de lo que se pensaba: las comorbilidades; tales como la obesidad (un grupo de riesgo muy importante), la hipertensión y la diabetes son las que más nos causan problemas. Sabemos que la carga viral que recibimos para contagiarnos tiene mucho que ver en la respuesta clínica, por lo que el personal de salud debe tener especial cuidado; también se han visto algunas asociaciones con factores genéticos, como el grupo sanguíneo y otros marcadores genéticos.

Ahora bien, ¿todos los que tenemos o han tenido contacto con el virus son sospechosos? Podríamos decir que sí, siempre y cuando tengan un cuadro clínico sugestivo. En la actualidad, la única forma de confirmar si se tiene la enfermedad es realizando las pruebas pertinentes, como la reacción en cadena de la polimerasa (PCR). Las inmunoglobulinas, tanto la lgC como la IgM, nos muestran que ya se tuvo la enfermedad, pero no si se encuentra activa.

¿Cuál es nuestro gran problema cuando hablamos de asmáticos o alérgicos? Los síntomas de COVID son muy similares, no iguales pero sí pueden llegar a confundir: tos, la sensación de cansancio, la falta de aire, rinorrea. Además, cabe señalar que pueden coexistir los dos padecimientos.

¿Cuál podría ser la diferencia? La presencia de sibilancias y la respuesta al tratamiento. Por ejemplo, si tenemos un paciente que se diagnostica o se sospecha de COVID y le damos un broncodilatador no va a cambiar su situación, no va a mejorar, posiblemente pueda respirar un poco mejor, pero hasta ahí.

\section{PROTOCOLO DE MANEJO DE PACIENTES ALÉRGICOS SOSPECHOSOS DE COVID}

¿Qué nos recomienda la Academia Europea y la Organización Mundial de Alergia? ¿Cómo atender a estos pacientes alérgicos cuando tenemos sospecha o cuando van al consultorio? Lo primero es tener un protocolo de manejo, cada uno de los profesionales de la salud debemos ver la manera de ayudar al personal y a los pacientes. Siempre se debe pensar en todos como un equipo, no dejar nada descubierto y asegurar una buena comunicación para generar seguridad.

El protocolo es para ayudar a pacientes y al personal, por lo que todo el equipo de salud del consultorio debe reunirse para decidir qué van a hacer, a dónde los van a mandar, qué les van a informar, dónde les van a conseguir los trípticos, los cubrebocas, dónde van a hacer todas las cosas que se necesitan ante un paciente que no saben cómo está hasta el momento en que llega. Asimismo, se debe tener una buena comunicación para que el paciente les tenga confianza; si el equipo de salud desde un principio duda qué va a hacer, el paciente no les hará caso. Además, tienen que protegerse ellos primero para proteger a los pacientes; estos últimos deben tener claro que si no es una visita urgente no deben hacerla, pues para eso están las consultas a distancia, las Ilamadas telefónicas, la telemedicina, entre muchas opciones más (el teléfono puede ser de gran ayuda, no debe ser descartado). También se debe modificar la sala de espera para evitar aglomeraciones. Todo debe estar listo para que el paciente pueda ser evaluado rápidamente e identificar si tiene o no sospecha de la enfermedad.

¿Cuál va a ser nuestro protocolo inicial? En principio prevalorar al paciente; al pedir la cita debemos preguntarle: «¿Por qué quiere venir?» Si los síntomas que dice tener son consistentes con la enfermedad, lo más probable es que no sea conveniente que vaya al consultorio de un alergólogo, sino donde sean especialistas en atender COVID. Segundo, si tiene un asma leve y está controlado no es necesario que acuda al consultorio, podemos seguir su tratamiento de manera telefónica; si es un asma grave sí necesitamos verlo, pues la exploración es de gran importancia.

Se ha determinado que el virus no sólo se transmite a través de las gotitas de saliva que entran por nuestra nariz y boca, sino que también accede por los ojos. De ahí la necesidad de no tocarse la cara porque podemos llevar el virus a todos lados y de utilizar máscaras, mascarillas, gafas protectoras o lentes cuando estemos frente al paciente.

¿Cómo debemos tener nuestras instalaciones? Deben estar bien ventiladas, procurar no tener aire acondicionado, ya que éste hará que circule todo el aire (a menos que tengamos un flujo de extracción de aire con un flujo continuo); sin embargo, 
por lo general, eso no lo tienen los consultorios. Sanitizar, utilizar la sana distancia y evitar juguetes o muñecos en los consultorios. Entre pacientes debemos limpiar nuestra área, estar preparados como médicos para evitar contagios, pues estamos en mayor riesgo que las personas que no están en estos espacios. Debemos utilizar caretas protectoras o protección ocular; no es necesario utilizar una mascarillas N95 para revisar a un paciente que no tenga ningún dato sospechoso de COVID, pero sí requerimos una mascarilla o cubrebocas quirúrgicos o tricapas; lavarse las manos frecuentemente antes y después de ver al paciente; utilizar guantes cuando tengamos que revisar narizy boca, después quitarnos los guantes y de nueva cuenta lavarnos las manos.

¿Qué es lo que sí puede hacer en el consultorio el alergólogo? Las pruebas cutáneas, con la debida higiene; estar bien preparados (con los guantes, todo esterilizado y en buen estado); otorgar inmunoterapia, sobre todo la sublingual (cuando hay inmunoterapia subcutánea tiene que ir a la clínica a aplicársele y por lo tanto estamos aumentando el riesgo de contagio cada vez que acuda); hay que evitar el tratamiento nebulizado, sabemos que es una parte muy importante en el tratamiento de pacientes pequeñitos, al nebulizar se producen aerosoles y eso puede ser un factor muy importante para el contagio. Si es indispensable utilizarlo, el personal de salud debe prepararse con el equipo completo de protección. No se debe realizar espirometría, ni pruebas de reto a menos que sean indispensables y hay que hacerlo con muchísimo cuidado, porque son de gran riesgo de contagio.

La Organización Mundial de Alergia publicó resultados de encuestas sobre lo que le preocupa a las personas en Europa. El primer punto era: «tengo asma y alergia y estoy preocupado»; las respuestas que encontraron fueron que el asmático está en el grupo de mayor riesgo, pues tiene una enfermedad pulmonar crónica, pero al mismo tiempo no se demostró que hubiera más gravedad que en otros grupos aparte de las comorbilidades de obesidad, hipertensión y diabetes; simplemente que el paciente esté controlado y que no pierda su control. ¿Cómo hacemos para que no pierda el control? El paciente debe seguir las indicaciones de su médico. Segundo, no estar con personas enfermas, no asistir a reuniones masivas, a eventos y tener todos los cuidados necesarios, como lavarse las manos en una forma eficiente y frecuente, no tocarse la cara sin haberse lavado las manos para evitar el contagio de cada mano.

\section{CONCLUSIONES}

Por último, la recomendación es que el paciente debe conocer su inhalador y cómo usarlo (éste puede ser su salvavidas), evitar los agentes desencadenantes, tener un plan por escrito bien específico de cómo manejarse, tener suficiente medicamento para no tener que salir de urgencia a buscarlo, hacer sus ejercicios respiratorios que son siempre indispensables en el paciente asmático, y siempre mantenerse en contacto con su médico.

Con esto, podemos decir que siempre hay que sacar una ganancia de todas las pérdidas, tenemos que aprender, y lo más importante: la comunicación dentro y fuera de casa, con los médicos, con el personal de salud, con las autoridades; equilibrar nuestros horarios para ayudarnos, usar medidas higiénicas dentro de nuestra casa, y sobre todo aprender a vivir en familia, cosa que muchas veces se nos ha olvidado.

\section{AGRADECIMIENTOS}

Agradecimiento a los alumnos pasantes de servicio social Enf. Belén Pérezy QFB José Eduardo Moreno Sanjuan de las licenciaturas de Enfermería y Química Farmacéutica Biológica por su colaboración en la transcripción del texto.

\section{LECTURAS RECOMENDADAS}

1. Global Initiative for Asthma. Global Strategy for Asthma Management and Prevention. Revised.

2. Taussing LM, Wright AL, Holberg CJ, Halonen M, Morgan WJ, Martínez FD. Tucson children's respiratory study: 1980 to present. J Allergy Clin Immunol. 2003; 117 (4): 661-675; quiz 676.

3. Clobal Strategy for Asthma Management and Prevention. Updated 2012. Clobal Initiative for Asthma 2012.

4. Clobal Strategy for Asthma Management and Prevention. Updated 2012. Clobal Initiative for Asthma 2014.

5. Global Initiative for Asthma. Updated 2010.

6. Lai C. Global variation in the prevalence and severity of asthma symptoms: Phase III of ISAAC. Thorax. 2009; 64: 476-483. 
7. Castro-Rodríguez JA. Hollberg CJ, Wright AL. Martinez FD. A clinical index to define risk of asthma in young children with recurrent wheezing. Am J Respir Crit Care Med. 2000; 162 (4 Pt 1): 1403-1406.

8. Papadopoulos NG, Arakawa H, Carlsen KH, Custovic A, Cern J et al. International consensus on (IÇON) pediatric asthma. Allergy. 2012; 67 (8): 976-997.

9. Ortiz-Prado E, López-Cortésk A. Clinical, molecular, and epidemiological characterization of the SARS-CoV-2 virus and the Coronavirus Disease 2019 (COVID-19), a comprehensive literature review. Diagnostic Microbiology \& Infectious Disease. 2020; 98 (1): 115094. Available in: https:// doi.org/10.1016/j.diagmicrobio.2020.115094.

10. https://www.aebm.org/comites-main/comite-de-calidadgestion-seguridad-y-evidencia/743-covid-19-perspectivadesde-el-laboratorio-c\%C3\%ADnico.html.

11. American Centers for Disease Control and Prevention. Available in: https://www.cdc.gov/Coronavirus/2019-ncov/ healthcare-facilities/index.html.

12. www.worldallergy.org 